Uniwersytet PrzyrodniczoHumanistyczny w Siedlcach

Siedlce University of Natural Sciences and Humanities

https://bazawiedzy.uph.edu.pl

\begin{tabular}{|l|l|}
\hline Publikacja / Publication & $\begin{array}{l}\text { Methyl jasmonate stimulates biosynthesis of 2-phenylethylamine, phenylacetic acid } \\
\text { and 2-phenylethanol in seedlings of common buckwheat, } \\
\text { Horbowicz Marcin, Wiczkowski Wiesław, Sawicki Tomasz, Szawara-Nowak Dorota, } \\
\text { Sytykiewicz Hubert, Mitrus Joanna Małgorzata }\end{array}$ \\
\hline $\begin{array}{l}\text { DOI wersji wydawcy / Published } \\
\text { version DOI }\end{array}$ & http://dx.doi.org/10.18388/abp.2014_929 \\
\hline $\begin{array}{l}\text { Adres publikacji w Repozytorium } \\
\text { URL / Publication address in } \\
\text { Repository }\end{array}$ & https://bazawiedzy.uph.edu.pl/info/article/UPHe81bb76bb6774b6da4fdb8ce0bfld151/ \\
\hline $\begin{array}{l}\text { Data opublikowania w Repozytorium / } \\
\text { Deposited in Repository on }\end{array}$ & 22 paź 2021 \\
\hline Rodzaj licencji / Type of licence & Attribution CC BY _ \\
\hline & $\begin{array}{l}\text { Horbowicz Marcin, Wiczkowski Wiesław, Sawicki Tomasz, Szawara-Nowak Dorota, } \\
\text { Sytykiewicz Hubert, Mitrus Joanna Małgorzata: Methyl jasmonate stimulates } \\
\text { biosynthesis of 2-phenylethylamine, phenylacetic acid and 2-phenylethanol in } \\
\text { seedlings of common buckwheat, Acta Biochimica Polonica, Polish Academy of } \\
\text { Science, vol. 62, no. 2, 2015, pp. 235-240, DOI:10.18388/abp.2014_929 }\end{array}$ \\
\hline
\end{tabular}




\title{
Methyl jasmonate stimulates biosynthesis of 2-phenylethylamine, phenylacetic acid and 2-phenylethanol in seedlings of common buckwheat
}

\author{
Marcin Horbowicz ${ }^{1 凶}$, Wiesław Wiczkowski², Tomasz Sawicki², Dorota Szawara-Nowak², \\ Hubert Sytykiewicz ${ }^{1}$ and Joanna Mitrus ${ }^{1}$
}

1Siedlce University of Natural Sciences and Humanities, Faculty of Natural Sciences, Siedlce, Poland; 2 Institute of Animal Reproduction and Food Research, Polish Academy of Sciences, Olsztyn, Poland

\begin{abstract}
Methyl jasmonate has a strong effect on secondary metabolizm in plants, by stimulating the biosynthesis a number of phenolic compounds and alkaloids. Common buckwheat (Fagopyrum esculentum Moench) is an important source of biologically active compounds. This research focuses on the detection and quantification of 2-phenylethylamine and its possible metabolites in the cotyledons, hypocotyl and roots of common buckwheat seedlings treated with methyl jasmonate. In cotyledons of buckwheat sprouts, only traces of 2-phenylethylamine were found, while in the hypocotyl and roots its concentration was about 150 and 1000-times higher, respectively. Treatment with methyl jasmonate resulted in a 4-fold increase of the 2-phenylethylamine level in the cotyledons of 7-day buckwheat seedlings, and an 11-fold and 5-fold increase in hypocotyl and roots, respectively. Methyl jasmonate treatment led also to about 4-fold increase of phenylacetic acid content in all examined seedling organs, but did not affect the 2-phenylethanol level in cotyledons, and slightly enhanced in hypocotyl and roots. It has been suggested that 2-phenylethylamine is a substrate for the biosynthesis of phenylacetic acid and 2-phenylethanol, as well as cinnamoyl 2-phenethylamide. In organs of buckwheat seedling treated with methyl jasmonate, higher amounts of aromatic amino acid transaminase mRNA were found. The enzyme can be involved in the synthesis of phenylpyruvic acid, but the presence of this compound could not be confirmed in any of the examined organs of common buckwheat seedling.
\end{abstract}

Key words: elicitation, Fagopyrum esculentum, phenylacetic acid, 2-phenylethanol, 2-phenylethylamine

Received: 04 November, 2014; revised: 09 January, 2015; accepted: 04 March, 2015; available on-line: 09 April, 2015

\section{INTRODUCTION}

Elicitation is recognized as an efficient method to increase the accumulation of secondary metabolites in plants (reviewed by Karuppusamy, 2009). One of the most frequently used elicitors is methyl jasmonate (MJ), which induces production of terpenoids, alkaloids and phenolic compounds (Wasternacks, 2007; De Geyter et al., 2012; Ruiz-García \& Gómez-Plaza, 2013). For instance, MJ increased content of various phenolic compounds in sprouts of common buckwheat (Fagopyrum esculentum Moench) (Horbowicz et al., 2011a; Kim et al., 2011).

2-Phenylethylamine (PEA) rarely occurs in plants, and its physiological role remains unclear (Smith, 1977; Shabana et al., 2006). It is product of L-phenylalanine (L-PHE) decarboxylation by aromatic L-amino acid decarboxylase (Smith, 1977). PEA often serves as an indicator of food quality and freshness, since it can be synthesized by fungi and bacteria contaminating the foodstuffs (Onal et al., 2013). In tomato fruit, PEA can be transformed into phenylacetaldehyde (PAAld), which is further converted to 2-phenylethanol (PE), an important component of tomato aroma (Tieman et al., 2006; 2007). PE is also a major constituent of rose flower scent (Sakai et al., 2007), and various fruits (Aubert et al., 2005). In rose flowers, PE is biosynthesized from L-PHE via PAAld by aromatic amino acid decarboxylase (AADC) and phenylacetaldehyde reductase (Sakai et al., 2007). In protoplast isolated from rose petals, aromatic amino acid aminotransferase transforms L-PHE to phenylpyruvic acid, which is then converted to PAAld and subsequently to PE (Hirata et al., 2012). PAAld, an important component of aroma, has also been found in buckwheat seeds (Janeš et al., 2009). Moreover, PE and PAAld have been detected among volatile flavor compounds of boiled buckwheat flour (Yajima et al., 1983).

Biosynthesis of phenylacetic acid (PAA) in plants probably occurs with the participation of aromatic aminoacid transaminase (AAT) which can produce phenylpyruvate from the L-PHE (Gamborg \&Wetter, 1963; Tomè et al., 1975). Then, decarboxylation and subsequent oxidation of phenylpyruvate leads to PAAld and PAA. PAA was identified as a natural auxin-like growth regulator in plants, but its full physiological role is not clear (Wightman \& Lighty, 1982; Morris \& Johnson, 1987; Ludwig-Müller \& Cohen, 2002).

Common buckwheat is a dicotyledonous plant from Polygonaceae family. Buckwheat sprouts are a rich source of flavonoids, and other phenolic compounds (Kim et al., 2004; 2011). Flavonoids are derived from L-PHE, and PEA is also synthesized from this amino acid. Enormous accumulation of PEA in buckwheat

e-mail: mhorbowicz@uph.edu.pl

Abbreviations: AADC, amino acid decarboxylase; AAT, aromatic amino acid transaminase; GAPDH, glyceraldehyde 3-phosphate dehydrogenase; PAA, phenylacetic acid; PAAld, phenylacetaldehyde; $P E$, 2-phenylethanol; PEA, 2-phenylethylamine; L-PHE, L-phenylalanine; MAO, monoamine oxidase; MJ, methyl jasmonate 
seedlings treated with MJ could have an impact on the synthesis of flavonoids. It seems that such substrate competition may be in buckwheat hypocotyl. In this buckwheat organ MJ inhibits the synthesis of anthocyanins, and stimulates the production of PEA (Horbowicz et al., 2011b). On the other hand, is not fully understood the reason for the accumulation of PEA, as well as its further metabolic transformation. It is likely that PEA can be a substrate in the formation of PAA, PAAld and PE in buckwheat. This study focuses on the detection and quantification of PEA and its possible metabolites in organs of common buckwheat seedlings treated with MJ. An additional objective has been to conduct genetic tests describing the biosynthesis of PEA and its metabolites.

\section{MATERIAL AND METHODS}

Preparation of plant samples. Seedlings of common buckwheat (cv. Hruszowska) were prepared by germination of seeds between two layers of wet filter paper which were then rolled and inserted in a $2.5 \mathrm{~L}$ beaker containing about $200 \mathrm{~cm}^{3}$ of tap water. The germination proceeded in darkness at $24 \pm 1^{\circ} \mathrm{C}$. After four days the seedlings were transferred to a growth chamber at $22 \pm 2{ }^{\circ} \mathrm{C} / 18 \pm 2^{\circ} \mathrm{C}$ (day/night: $16 \mathrm{~h} / 8 \mathrm{~h}$ ). Light $\left(100 \mu \mathrm{mol} \times \mathrm{m}^{-2} \times \mathrm{s}^{-1}\right)$ was provided by high-pressure sodium lamps. Then, the half of seedlings were treated with atmospheric vapors of methyl jasmonate (MJ, Sigma Aldrich). A 3-cm-wide ribbon of filter paper containing a drop of MJ (56 mg) was placed against the inner wall of the beaker containing the rolls with the seedlings, and the jar was immediately closed tightly with a transparent silicon film. The concentration of atmospheric MJ was calculated a $0.1 \mathrm{mM}$ (assuming its complete evaporation). Immediately after germination, and after four or seven days of growth in such conditions, organs (roots, hypocotyl and cotyledons) of control plants and MJ treated were subjected to analyses. The seedlings were taken for analyses between 9 and $10 \mathrm{am}$. For molecular analyses the plant samples were lyophilized for a period of $72 \mathrm{~h}$ in a freeze dryer Christ Alpha 1-2 LD+. For genetic tests after 4 days of MJ treatment the seedling organs have been taken, which was then stored until analysis at $-85^{\circ} \mathrm{C}$.

Analysis of metabolites by HPLC-MS/MS. About $0.05 \mathrm{~g}$ of freeze-dried and pulverized samples of cotyledons, hypocotyl and roots of buckwheat was extracted with $2 \mathrm{~mL}$ of $80 \%$ methanol by 60 -s sonication (VC 750, Sonics \& Materials, USA) and 30-s vortexing. Subsequently, the extraction was conducted using Thermomixercomfor (Eppendorf) by shaking at $20^{\circ} \mathrm{C}$ with amplitude of $600 \mathrm{rpm}$ for $24 \mathrm{~h}$. After centrifugation $\left(20 \mathrm{~min}, 13000 \times \mathrm{g}, 4^{\circ} \mathrm{C}\right)$, the obtained supernatant was stored at $-80^{\circ} \mathrm{C}$ until analysis. Analysis of 2-phenylethylamine (PEA), 2-phenylethanol (PE) and phenylacetic acid (PAA) was carried out by using HPLC-MS/MS system consisting of two pumps (LC-20AD), autosampler (SIL-20AC $\mathrm{HT}_{\mathrm{HT}}$ ), column oven $\left(\mathrm{CTO}-10 \mathrm{AS}_{\mathrm{VP}}\right)$, degasser (DGU-20A $)$, system controller (SCL-10 $\mathrm{A}_{\mathrm{VP}}$ ) and QTRAP 5500 mass spectrometer (AB SCIEX, Canada) with a triple quadrupole, an ion trap, and an ion source of electrospray ionization. A 5 -mL aliquot of the extract was injected to the HPLC-MS/MS system equipped with a $150 \times 2.1 \mathrm{~mm}$ i.d. XBridge C18, $3.5 \mu \mathrm{m}$ column (Waters, Milford, USA). Chromatography was performed

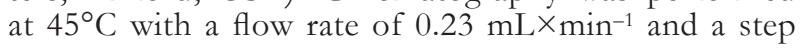

gradient system of water/formic acid (99:1, v/v, phase A) and acetonitrile/formic acid (99:1, v/v, phase B) comprising $10-80-80-10-10 \% \mathrm{~B}$ at $0-10-15-16-35$ min. Qualitative analysis consisted of, among others, scanning in a positive and negative ion mode. Scanning fragment ions formed from the decay of the parent ion was also performed. This method was used in the search for presence of fragmentation ions of phenylpyruvate. The identity of PEA, PE, PAA and PAAld was confirmed by comparing the HPLC retention times and MS/MS spectra to the ones obtained for authentic standards (Sigma Aldrich). Quantitative analysis was performed by means of the MRM (Multiple Reaction Monitoring) method using positive ionization for: 2-phenylethylamine $(122-105 \mathrm{~m} / \mathrm{z})$, phenylacetaldehyde (121-91 $\mathrm{m} / \mathrm{z})$, and an unknown compound (probably cinnamoyl 2-phenylethylamide, 251-77 m/ $\mathrm{z}$ ). In the case of 2-phenylethanol and phenylacetic acid, negative ionization (range 121-77 and 135-91 m/ $\mathrm{z}$, respectively) was applied. Optimal identification of the compounds was achieved under the following conditions: curtain gas: $20 \mathrm{~L} / \mathrm{min}$; collision gas: $9 \mathrm{~L} / \mathrm{min}$; ion-spray voltage: $5300 \mathrm{~V}$ (positive ionization), -4500 $\mathrm{V}$ (negative ionization); temperature: $550^{\circ} \mathrm{C}$; 1 ion source gas: $55 \mathrm{~L} / \mathrm{min}$; 2 ion source gas: $70 \mathrm{~L} / \mathrm{min}$; declustering potential: $+112 \mathrm{~V}$ (positive ionization), -40 and $-50 \mathrm{~V}$ (negative ionization); entrance potential: 10 $\mathrm{V}$ (positive ionization), $-10 \mathrm{~V}$ (negative ionization); collision energy: $20 \mathrm{eV}$ (positive ionization), 17 and 13 $\mathrm{eV}$ (negative ionization); collision cell exit potential: $20 \mathrm{~V}$ (positive ionization), -18 and $-10 \mathrm{~V}$ (negative ionization).

Measurement of aromatic amino acid transaminase gene expression. Total RNA was isolated from the organs of buckwheat seedlings with the Spectrum Plant Total RNA Kit (Sigma Aldrich), and residual genomic DNA was removed using On-Column DNase I Digestion Set (Sigma Aldrich, Poland). Qualitative and quantitative analyses of the RNA were performed using an Epoch UV-Vis microplate spectrophotometer. Subsequently, the intact total RNA (1 $\mu g)$ was used for reverse transcription using the High Capacity cDNA Reverse Transcription Kit with RNase Inhibitor (Life Technologies, Poland). Negative controls (no template and no reverse transcriptase) were included. The mRNA level of the aromatic amino acid transaminase $(A A T)$ gene in MJ-treated and control seedlings of $F$. esculentum was assessed with the use of quantitative real-time polymerase chain reaction (RTqPCR). Glyceraldehyde 3-phosphate dehydrogenase $(G A P D H)$ gene was selected as the reference gene. The mRNA level of the GAPDH gene was quantified using Custom TaqMan Gene Expression Assay (Life Technologies, Poland); the following primers and TaqMan fluorescent probe were used: forward primer: TGGAGCTGCTAAGGCTGTTG, reverse primer: GCCATTCCAGTCAACT'T'TCCAT'T, and probe: FAM-CAACACTGGCAACACC-NFQ. The relative expression of the $A A T$ gene was quantified using the TaqMan Gene Expression Assay (no. At02227046_g1, Life Technologies). The reaction mixture consisted of $4 \mu \mathrm{l}$ of cDNA, $1 \mu \mathrm{l} 20 \times$ TaqMan Gene Expression Assay, $10 \mu \mathrm{l} 2 \times$ TaqMan Fast Universal PCR Master Mix, and $5 \mu \mathrm{l}$ RNase-free (PCR grade) water. Measurement of transcript amounts was performed using the fast mode of StepOne Plus Real-Time PCR System and StepOnePlus Software v2.3 (Life Technologies, USA). Quantification of the relative level of $A A T$ mRNA was carried out according to the $\Delta \Delta C_{\mathrm{T}}$ 
method described by Livak \& Schmittgen (2001). The obtained data are expressed as average n-fold changes \pm standard deviation (S.D.) in levels of $A A T$ transcript in comparison to untreated plants. The experiments were performed with three independent biological replicates.

Statistical analysis. The analyses of PEA, PE and PAA levels were determined in three technical replicates, and the results are presented as means \pm standard deviation (S.D.). The differences between the contents of analyzed compounds in the treated and control seedlings were analyzed statistically using Student's $t$-test, $P<0.01$.

One-way analysis of variance (ANOVA) with Tukey's post hoc test was used to evaluate the significance of differences of the $A A T$ gene transcript between MJtreated and control seedlings $(P<0.05$ was considered significant). Statistical calculations were conducted using STATISTICA 10 software (StatSoft, Poland).

\section{RESULTS}

HPLC/MS/MS analysis showed the presence of 2-phenylethylamine (PEA), 2-phenylethanol (PE) and phenylacetic acid (PAA) in the cotyledons, hypocotyl and
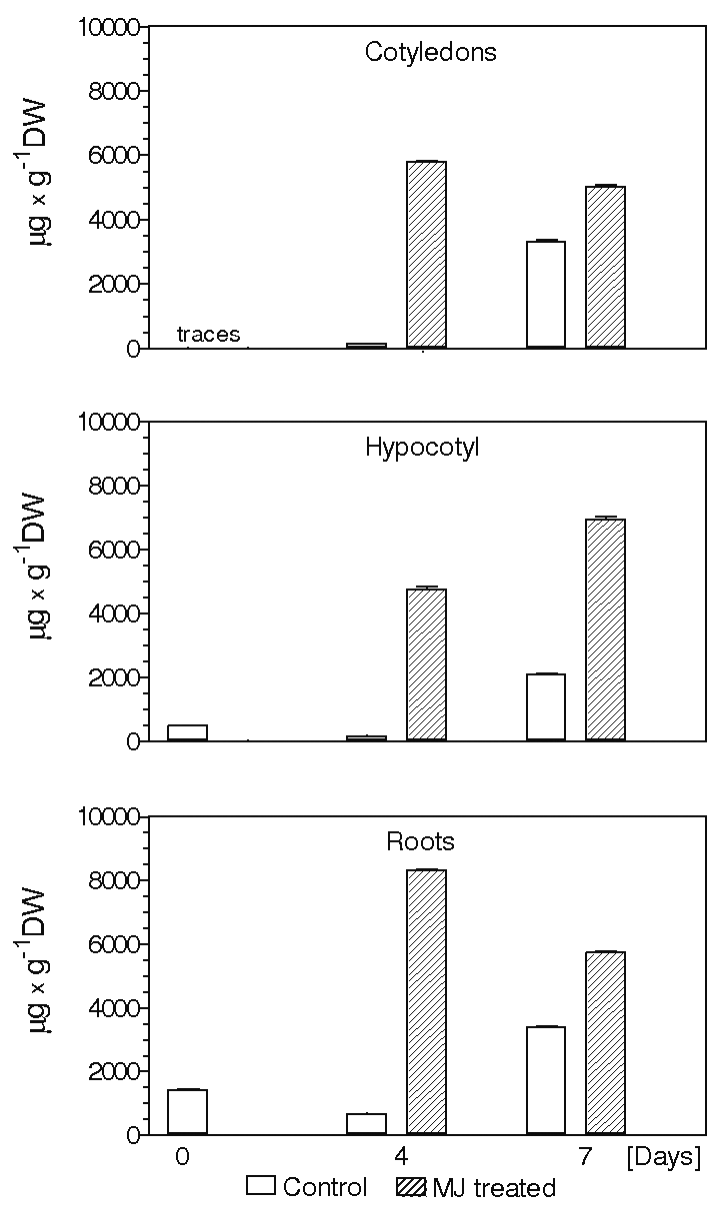

Figure 1. Effect of de-etiolation and methyl jasmonate (MJ) on 2-phenylethylamine (PEA) content in organs of common buckwheat seedling.

The results for control and MJ-treated plants were significantly different $(P<0.01)$ : for cotyledons, hypocotyl, and roots (4-days and 7-days treated). Seedlings prepared within 4-days sprouting in the darkness were transferred to the growth chamber and then treated with atmospheric MJ for 4- or 7-days. Chemical analyzes have been performed immediately after germination, and after 4 and 7 days of treatment. roots of buckwheat seedlings, as confirmed by comparing their fragmentation spectra and retention times to the obtained commercial standards. However, this analysis did not confirm the presence of phenylacetaldehyde (PAAld) in the examined organs.

Etiolated buckwheat seedlings obtained after 4-day germination in darkness have light-yellow cotyledons, 5-7 cm tall white hypocotyl and a root system with the primary root, $8-10 \mathrm{~cm}$ long. In cotyledons of such seedlings, a very low level of PEA was found (Fig. 1). In hypocotyl, its concentration was about 150 times higher than in cotyledons, and in roots about 1000 times. During the first four days of de-etiolation, the level of PEA increased in cotyledons and decreased in hypocotyl and roots. After seven days growth in the light conditions, the content of PEA increased in the all organs, and was almost equal in cotyledons and roots, and slightly lower in hypocotyl (Fig. 1).

Methyl jasmonate (MJ) caused enormous increase of the PEA level in all the examined tissues of buckwheat seedlings in comparison with control plants at the same stage. It was particularly spectacular after 4 days of treatment with MJ, when PEA reached the highest level in roots and a slightly lower, but still a high one in hypocotyl and cotyledons. After seven days of MJ action the PEA level in cotyledons was 4-fold higher, 11-fold higher in hypocotyl, and 5-fold in roots compared to control (Fig. 1).

The PAA content remained constant throughout of de-etiolation process in cotyledons and hypocotyl of seedlings (Fig. 2). In roots, it rose only slightly during the first four days, and then increased 5-fold at 7 days of de-etiolation. A four-day use of MJ led to a 3-fold increase of PAA content in cotyledons and roots, and a about 7-fold in the hypocotyl. After seven-days use of MJ action a further accumulation of PAA was observed, to a level exceeding 5, 9 and 4-fold its content in cotyledons, hypocotyl and roots of control plants, respectively (Fig. 2).

2-Phenylethanol (PE) was present in the organs studied at much lower (ng) concentrations than PEA and PAA ( $\mu$ g) (Fig. 3). In cotyledons and hypocotyl its level remained relatively stable during 4 or 7 days of de-etiolation, and rose gradually in roots.

The use of MJ (for 4 or 7 days) did not affect the content of the PE in cotyledons, but significant increase occurred in the hypocotyl after 4 days, and in roots after 7 days of MJ treatment.

To study the effect of MJ on the expression of genes encoding enzymes involved in the metabolism of L-phenylalanine to PEA, PAA, PAAld and PE, we attempted to quantitate mRNA levels of L-phenylalanine decarboxylase, alcohol dehydrogenase, aldehyde oxidase 1 and 2, aromatic aldehyde synthase, copper amine oxidase 1, lipoxygenase and aromatic acid transferase (AAT). Since no nucleotide sequences for these genes from F. esculentum in GenBank or other databases are available, we selected homologous genes from other plants related to the Fagopyrum genus (e.g. Polygonum minus Huds., Arabidopsis thaliana L.). However, Custom TaqMan Gene Expression Assays (Life Technologies, Poland) targeting were ineffective with cDNA from Fagopyrum esculentum. Presumably, the prepared primers and/or TaqMan probes were not sufficiently complementary to the buckwheat cDNA templates. The only exception was AAT gene, for which specific amplification was achieved.

Table 1 shows the results of the $A A T$ mRNA quantitation in diverse organs of seedlings subjected to $\mathrm{MJ}$ 

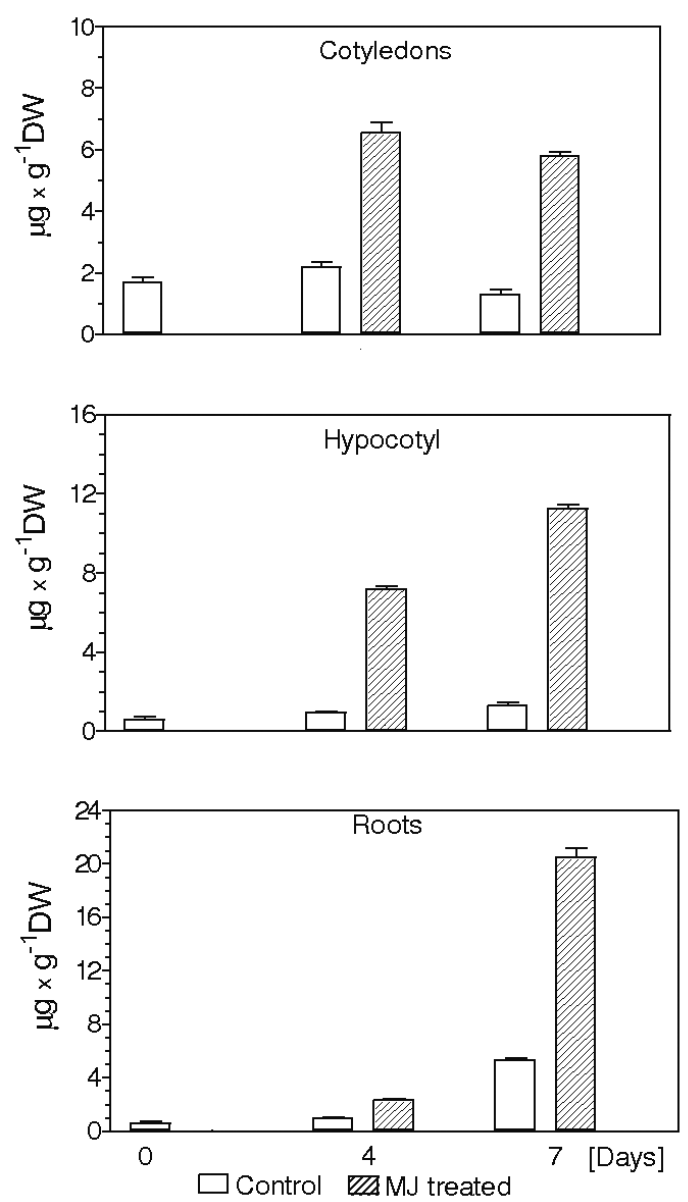

Figure 2. Effect of de-etiolation and methyl jasmonate (MJ) on phenylacetic acid (PAA) content in organs of common buckwheat seedling.

The results for control and MJ-treated plants were significantly different $(P<0.01)$ : for cotyledons and hypocotyls $(4-$ and 7 -days treated); for roots (7-days treated). For roots (4-days treated) the differences were not significant. Seedlings prepared within 4-days sprouting in the darkness were transferred to the growth chamber and then treated with atmospheric MJ for 4- or 7-days. Chemical analyzes have been performed immediately after germination, and after 4 and 7 days of treatment.

(0.1 $\mathrm{mM}$ vapour) for four days compared to untreated seedlings.

In all the organs studied MJ enhanced the level of AAT mRNA. The highest (7.50-fold) was noted in roots, a moderate (5.22-fold) increase was in the hypocotyl, and the lowest (3.60-fold) in cotyledons. A oneway analysis of variance with Tukey's post hoc test

Table 1. Effect of MJ treatment on relative expression of $A A T$ gene in the seedlings of common buckwheat.

Seedlings prepared within 4-days sprouting in the darkness were transferred to the growth chamber and then treated with atmospheric MJ for 4-days. The data are presented as the mean AAT amount \pm S.D. Analysis of gene expression was performed in three biological and three technical replicates. Different letters denote significant differences between organs of treated seedlings and control at $P<0.05$.

\begin{tabular}{ll}
\hline Tested organ & $\begin{array}{l}\text { AAT level } \\
\text { (fold change in relation to control) }\end{array}$ \\
\hline Cotyledons & $3.60 \pm 0.11^{\mathrm{c}}$ \\
\hline Hypocotyl & $5.22 \pm 0.34^{\mathrm{b}}$ \\
\hline Primary root & $7.50 \pm 0.57^{\mathrm{a}}$ \\
\hline
\end{tabular}
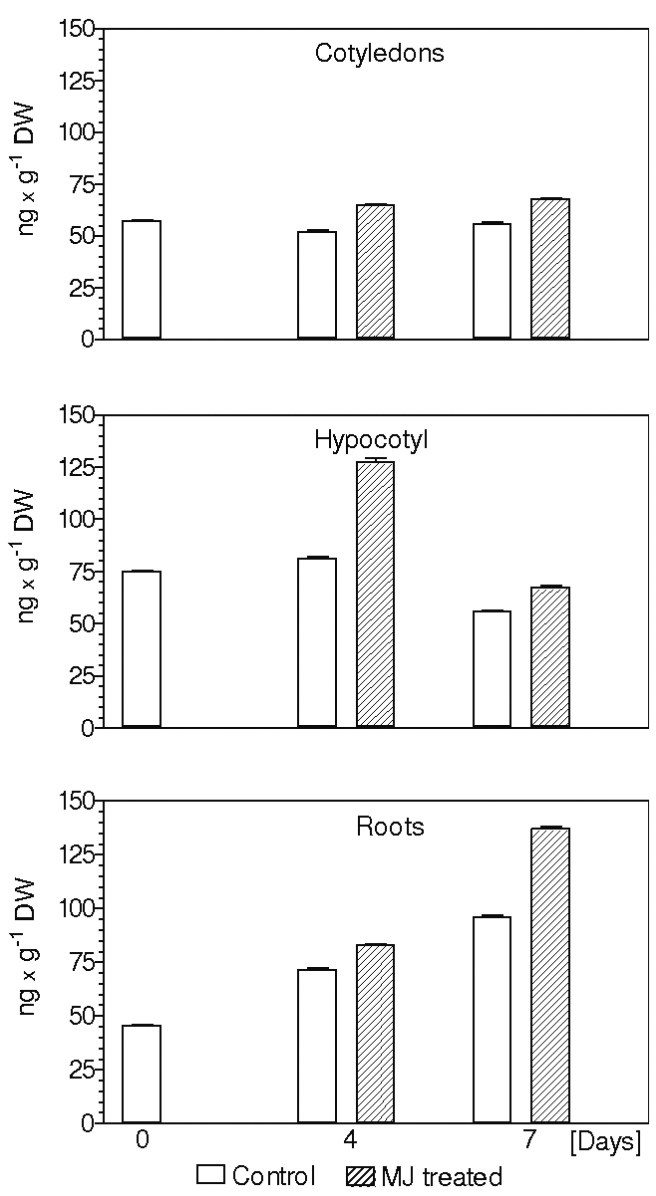

Figure 3. Effect of de-etiolation and MJ on 2-phenylethanol content in organs of common buckwheat seedling.

The results for control and $\mathrm{MJ}$-treated plants were significantly different $(P<0.01)$ : for hypocotyls, 4-days treated; for roots, 7 -days treated. For cotyledons (4- and 7-days treated), for roots (4-days treated) and for hypocotyls (7-days treated) the differences were not significant. Seedlings prepared within 4-days sprouting in the darkness were transferred to the growth chamber and then treated with atmospheric MJ for 4- or 7-days. Chemical analyzes have been performed immediately after germination, and after 4 and 7 days of treatment.

confirmed the statistical significance of the effect of MJ $\left(\mathrm{D}_{\mathrm{f}}=2 ; \mathrm{F}_{(2,6)}=6.467 ; P<0.0001\right)$.

\section{DISCUSSION}

A much lower content (traces) of PEA was found in cotyledons then in roots and the hypocotyl of etiolated buckwheat seedlings, which could indicate that PEA is synthesized in the roots in that phase of seedling growth, and then transported to other tissues during further development. Following exposure to light, as after 4 and 7 days of growth the content of PEA reached a similar level in all the examined organs. Such a phenomenon has been described for the first time. Remains, however, to determine whether it is the effect of light or plant growth. Also the differences between responses of organs studied to MJ were statistically significant.

Because of the scarce data on the role of PEA in plants, the finding remains just an assumption on this subject. There is no known reason for the accumulation of PEA and its possibly transport observed in young buckwheat seedlings. Smith (1977) formulated a hy- 
pothesis that plants may accumulate PEA as part of a defense system against insects. Another reason for the PEA presence could be its allelopathic properties (Szwed et al., 2014). It is known that buckwheat extracts suppress some weeds (Iqbal et al., 2005) and inhibit growth of wheat and lettuce seedlings (Mioduszewska et al., 2013).

One of the postulated routes of the metabolism of PEA in plants is its oxidation by monoamine oxidase (MAO). Indeed, a high specificity of MAO for PEA has been found in seedlings of Avena sativa (Zhang et al., 2012). MAO can oxidise PEA to PAAld, and a further reduction of PAAld to PE, catalyzed by phenylacetaldehyde reductase, has been described in tomato (Tieman et al., 2006; 2007) and in rose tissues (Sakai et al., 2007; Chen et al., 2011). However, the enzyme that oxidizes PAAld to PAA has not been characterized in plants yet. On the other hand, according to Ludwig-Müller \& Cohen (2002), the presence of nitrilase enzyme in nasturtium suggests that the biosynthesis of PAA uses the nitrilase pathway with a benzylglucosinolate precursor. Nitrilases are enzymes found in many plants, which convert nitriles to the corresponding carboxylic acids. For example, indole3-acetic acid (IAA) can be synthesised through the indole-3-pyruvic acid pathway or the tryptamine pathway (Mano \& Nemoto, 2012). The tryptamine pathway involves conversion of tryptophane into tryptamine, and then to indole-3-acetonitrile, which is further converted by a nitrilase into IAA. Nitrilases of Sorghum bicolor exhibited a high enzymatic activity towards 4-hydroxyphenyl-acetonitrile and phenylacetonitrile, and converted these compounds into hydroxyphenylacetic acid and PAA, respectively (Jenrich et al., 2007). It is possible that the latter mentioned metabolic pathway functions in the common buckwheat, although this requires further study.

PAA has a much weaker auxin activity than IAA (Wightman \& Lighty, 1982). However, the transport of PAA competes with IAA translocation, and may therefore affect the plant growth (Morris \& Johnson, 1987). An increased level of PAA as a result of MJ treatment in buckwheat organs, and consequently a reduced IAA transport, could be the major reason for the inhibition of root growth reported in our previous studies (Horbowicz et al., 2008). It is also speculated that PAA preferentially plays a role in the root interactions with soil microorganisms, which could explain its elevated level in roots of buckwheat seedlings (Morris \& Johnson, 1987). PAA has also some allelopathic activity (Szwed et al., 2014).

The role of PE in buckwheat seedlings is unknown. It could be a substrate for the biosynthesis of phenylacetaldehyde (PAAld), whose presence has been found in the scent of buckwheat seeds (Janeš et al., 2009). The presence of both PE and PAAld has also been confirmed in the flavor of boiled buckwheat flour (Yajima et al., 1983). According to our recent studies, PE has some allelopathic properties, because it inhibits of seedlings growth of several plant species (Szwed et al., 2014).

Searching for other possible route of PEA transformation in buckwheat seedlings we therefore undertook attempts to find another PEA metabolites. According to our previous studies trans-cinnamic acid is the major phenolic acid in organs of buckwheat seedling (Horbowicz et al., 2011a). Therefore, we searched for a compound which is a derivative of PEA and trans-cinnamic acid, cinnamoyl 2-phenylethylamide $\left(\mathrm{C}_{6} \mathrm{H}_{5}-\mathrm{CH}_{2}-\mathrm{CH}_{2} \mathrm{NH}-\mathrm{CO}\right.$ $\left.\mathrm{CH}=\mathrm{CH}-\mathrm{C}_{6} \mathrm{H}_{5}\right)$ could be such compound. It is an amide in which trans-cinnamic acid provides the acid moiety and 2-phenethylamine the amine moiety. In the mass spectra an ion at $\mathrm{m} /$ z 251.1376 (calculated mass: 251.1311) was observed. The ion at $m / z 251\left(\mathrm{M}^{+}\right.$;17) was fragmented to one at $m / z 234$ which was attributed to the loss of $\mathrm{NH}_{3}\left(\mathrm{M}^{+}-\mathrm{NH}_{3} ; 49\right)$. The support for the phenylethyl moiety come from an intense peak (100, base peak) at $\mathrm{m} / \mathrm{z}$. 105, likely corresponding to $\mathrm{C}_{6} \mathrm{H}_{5}-\mathrm{CH}_{2}-\mathrm{CH}_{2}^{+}$. Such a base peak $(m / z$ 105) has been observed also in spectra of N-phenylethyl-dodecanamide, N-phenylethyl-tridecanamide and $N$-(2-phenylethyl)-indomethacin amide (Metlin Scripps Database). Other peaks noted in our mass spectrum were the following $m / ₹: 77\left(\mathrm{C}_{6} \mathrm{H}_{5}{ }^{+} ; 6\right) ; 84$ (45); 122 $\left(\mathrm{C}_{6} \mathrm{H}_{5}-\mathrm{CH}_{2}-\mathrm{CH}_{2}-\mathrm{NH}_{3}{ }^{+} ; 34\right)$ and 130 . The peak at $\mathrm{m} /$ \% 130 (probably $\mathrm{C}_{6} \mathrm{H}_{5}-\mathrm{CH}=\mathrm{C}-\mathrm{CO}^{+} ; 6$ ) likely comes from the cinnamoyl part of the amide. The peak at $m / z 205(\mathrm{M}-46)$ is probably the result of McLafferty rearrangement. Thus, we suppose that PEA can be a substrate for the synthesis of cinnamoyl 2-phenylethylamide. However, a quantitative analysis of this compound was not possible due to a lack of a pure standard.

The positive linear relationship $(r=0.601, P<0.05)$ between PAA and PEA content, and between PAA and PE $(r=0.677, P<0.01)$ suggests their common biosynthetic pathway. Similarly, a positive linear relationship was also observed between the levels of PEA and cinnamoyl 2-phenylethylamide $(\mathrm{r}=0.611, P<0.05)$. In contrast no significant correlation between PE and PEA was found. The explanation for this situation is difficult. It is known that secondary metabolism in plants is complicated and regulated by a complex set of genes, encoding diverse regulators, modifiers, transporters, and enzymes responsible for the synthesis and release of elicitors (Kim et al., 2011).

The results of our study show that all the MJ-treated organs of buckwheat seedlings contained increased amounts of amino acid transaminases (AAT) mRNA. These results are in line with the suggestion that aromatic amino acid transaminases may be involved in the production of PE in tomato plants (Tieman et al., 2006) and also confirm previous studies on tyrosine amino acid transferase (TAT). Recently, Zhang et al. (2014) reported that MJ treatment significantly induced the transcriptional activity of TAT gene in hairy roots of Salvia miltiorrbiza. Earlier, a similar phenomenon was observed for TAT in a jasmonate-deficient mutant of Arabidopsis thaliana (Sandorf \& Holländer-Czytko, 2002).

The results obtained in our study suggest that the biosynthesis of PAA and PE in buckwheat tissues likely proceeds through phenylpyruvate, which can be obtained by the action of AAT. However, no signals confirming the presence of phenylpyruvate could be found in the mass spectra obtained here by LC-MS/MS method.

\section{CONCLUSIONS}

The obtained results do not allow us to conclude definitely as to the identity of biosynthetic pathway of phenylacetic acid and 2-phenylethanol. It seems that both routes are possible: by the deamination of L-phenylalanine to phenylpyruvic acid and/or by the oxidation of 2-phenylethylamine by a multifunctional enzyme or a set of enzymes. Further studies, particularly molecular ones, are necessary to resolve this problem. The occurrence of phenylacetic acid, 2-phenylethanol, and probably cinnamoyl 2-phenylethylamide in roots, hypocotyl and cotyledons of common buckwheat seedlings was confirmed for the first time. Their biosynthesis is stimulated by methyl jasmonate. 


\section{Acknowledgements}

The studies were supported by the National Science Centre, grant No. 2011/01/B/NZ9/02888.

\section{RERERENCES}

Aubert C, Baumann S, Arguel H (2005) Optimization of the analysis of flavor volatile compounds by liquid-liquid microextraction (LLME). Application to the aroma analysis of melons, peaches, grapes, strawberries, and tomatoes. I Agric Food Chem 53: 8881-8895.

Chen XM, Kobayashi H, Sakai M, Hirata H, Asai T, Ohnishi T, Baldermann S, Watanabe N (2011) Functional characterization of rose phenylacetaldehyde reductase (PAR), an enzyme involved in the biosynthesis of the scent compound 2-phenylethanol. J Plant Physiol 168: 88-95.

De Geyter N, Gholami A, Goormachtig S, Goossens A (2012) Transcriptional machineries in jasmonate-elicited plant secondary metabolizm. Trends Plant Sci 17: 349-359.

Gamborg OL, Wetter LR (1963) An aromatic amino acid transaminase from mung bean. Can J Biochem Phys 41: 1733-1740.

Hirata H, Ohnishi T, Ishida H, Tomida K, Sakai M, Hara M, Watanabe N (2012) Functional characterization of aromatic amino acid aminotransferase involved in 2-phenylethanol biosynthesis in isolated rose petal protoplasts. J Plant Physiol 169: 444- 451.

Horbowicz M, Chrzanowski G, Koczkodaj D, Mitrus J (2011a) The effect of methyl jasmonate vapors on content of phenolic compounds in seedlings of common buckwheat (Fagopyrum esculentum Moench). Acta Soc Bot Pol 80: 5-9.

Horbowicz M, Grzesiuk A, Dębski H, Koczkodaj D, Saniewski M (2008) Methyl jasmonate inhibits anthocyanins synthesis in seedlings of common buckwheat (Fagopyrum esculentum Moench). Acta Biol Cracov Bot 50: 71-78.

Horbowicz M, Kosson R, Wiczkowski W, Koczkodaj D, Mitrus J (2011b) The effect of methyl jasmonate on accumulation of 2-phenylethylamine and putrescine in seedlings of common buckwheat (Fagopyrum esculentum). Acta Physiol Plant 33: 897-903.

Iqbal Z, Hiradate S, Noda A, Isojima S, Fujii Y (2003) Allelopathic activity of buckwheat: isolation and characterization of phenolics. Weed Sci 51: 657-662.

Janeš D, Kantar D, Kreft S, Prosen H (2009) Identification of buckwheat (Fagopyrum esculentum Moench) aroma compounds with GCMS. Food Chem 112: $120-124$.

Jenrich R, Trompetter I, Bak S, Olsen CE, Moller BL, Piotrowski M (2007) Evolution of heteromeric nitrilase complexes in Poaceae with new functions in nitrile metabolism. Proc Natl Acad Sci USA 104: 18848-18853.

Karuppusamy S (2009) A review on trends in production of secondary metabolites from higher plants by in vitro tissue, organ and cell cultures. J Med Plants Res 3: $1222-1239$.

Kim HJ, Park KJ, Lim JH (2011) Metabolomic analysis of phenolic compounds in buckwheat (Fagopyrum esculentum Moench) sprouts treated with methyl jasmonate. J Agric Food Chem 59: 5707-5713.

Kim SL, Kim SK, Park CH (2004) Introduction and nutritional evaluation of buckwheat sprouts as a new vegetable. Food Res Int 37: 319-327.

Livak KJ, Schmittgen TD (2001) Analysis of relative gene expression data using real-time quantitative PCR and the $2^{-\Delta \Delta \mathrm{Ct}}$ method. Methods 25: 402-408.
Ludwig-Müller J, Cohen JD (2002) Identification and quantification of three active auxins in different tissues of Tropaeolum majus. Physiol Plant 115: 320-329.

Mano Y, Nemoto K (2012) The pathway of auxin biosynthesis in plants. I Exp Bot 63: 2853-2872.

Metlin Scripps Database http://metlin.scripps.edu/

Mioduszewska H, Klocek J, Horbowicz M, Wolska K (2013) Effect of water extracts from tissues of common buckwheat on seed germination and seedling growth of winter wheat and lettuce. Acta Sci Pol-Agric 12: 45-54.

Morris DA, Johnson CF (1987) Regulation of auxin transport in pea (Pisum sativum L.) by phenylacetic acid: inhibition of polar auxin transport in intact plants and stem segments. Planta 172: 408-416.

Onal A, Tekkeli SE, Onal C (2013) A review of the liquid chromatographic methods for the determination of biogenic amines in foods. Food Chem 138: 509-515.

Ruiz-García Y, Gómez-Plaza E (2013) Elicitors: a tool for improving fruit phenolic content. Agriculture-London 3: 33-52.

Sakai M, Hirata H, Sayama H, Sekiguchi K, Itano H, Asai T, Dohra H, Hara M, Watanabe N (2007) Production of 2-phenylethanol in roses as the dominant floral scent compound from L-phenylalanine by two key enzymes, a PLP-dependent decarboxylase and a phenylacetaldehyde reductase. Biosi Biotech Bioch 71: 2408-2419.

Sandorf I, Holländer-Czytko H (2002) Jasmonate is involved in the induction of tyrosine aminotransferase and tocopherol biosynthesis in Arabidopsis thaliana. Planta 216: $173-179$.

Shabana M, Gonaid M, Salama MM, Abdel-Sattar E (2006) Phenylalkylamine alkaloids from Stapelia birsuta L. Nat Prod Res 20: 710-714.

Smith TA (1977) Phenethylamine and related compounds in plants. Phytochemistry 16: 9-18.

Szwed M, Sławianowska J, Koczkodaj D, Mitrus J, Sytykiewicz H, Horbowicz M (2014) Allelopathic properties of extract and some metabolites present in the tissues of common buckwheat (Fagopyrum esculentum Moench) seedlings. Acta Sci Pol-Agric 13: 139-151.

Tieman DM, Taylor M, Schauer N, Fernie AR, Hanson AD, Klee HJ (2006) Tomato aromatic amino acid decarboxylases participate in synthesis of the flavor volatiles 2-phenylethanol and 2-phenylacetaldehyde. Proc Natl Acad Sci USA 103: 8287-8292.

Tieman DM, Loucas HM, Kim JY, Clark DG, Klee HJ (2007) Tomato phenylacetaldehyde reductases catalyze the last step in the synthesis of the aroma volatile 2-phenylethanol. Phytochemistry 68: 2660-2669.

Tomè F, Campedelli L, Bellini E (1975) Distribution of phenylalanine transaminase and phenylalanine ammonia-lyase activities in etiolated and light irradiated radish seedlings (Raphanus sativus L.). Experientia 31: 1119-1121.

Wasternack C (2007) Jasmonates: an update on biosynthesis, signal transduction and action in plant stress response, growth and development. Ann Bot 100: 681-697.

Wightman F, Lighty DL (1982) Identification of phenylacetic acid as a natural auxin in the shoots of higher plants. Physiol Plant 55: 17-24.

Yajima I, Yanai T, Nakamura M, Sakakibara H, Uchida H, Hayashi K (1983) Volatile flavor compounds of boiled buckwheat flour. Agr Biol Chem 47: 729-738.

Zhang S, Yan Y, Wang B, Liang Z, Liu Y, Liu F, Qi Z (2014) Selective responses of enzymes in the two parallel pathways of rosmarinic acid biosynthetic pathway to elicitors in Salvia miltiorrhiza hairy root cultures. J Biosci Bioeng 117: 645-651.

Zhang YM, Livingstone JR, Hirasawa E (2012) Purification and characterisation of monoamine oxidase from Avena sativa. Acta Physiol Plant 34: 1411-1419. 